\title{
The visualisation of fingermarks on Pangolin scales using gelatine lifters
}

\author{
Moorat, G.*, Reed, J.*, Pamment, N.*, Bleay, S. ${ }^{\circ}$, Amaral, M.A. ${ }^{\circ}$, Chappell, B.*, Plowman, \\ C. ${ }^{+}$Smith, P.A.* (corresponding author) \\ * University of Portsmouth \\ ${ }^{\circ}$ London South Bank University \\ + Wildlife Conservation Society \\ Corresponding Author: P.Smith paul1.smith@port.ac.uk
}

\begin{abstract}
Recent media reports document the plight of the Pangolin and its current position as "the most trafficked mammal in the world". They are described by some as scaly anteaters as all species are covered in hard keratinous tissue in the form of overlapping scales acting as a "flexible dermal armour". It is estimated that between 2011 and 2013, 117,000 to 234,000 pangolins were slaughtered, but the seizures may only represent as little as $10 \%$ of the true volume of pangolins being illegally traded. In this paper, methods to visualise fingermarks on Pangolin scales using gelatine lifters is presented. The gelatine lifters provide an easy to use, inexpensive but effective method to help wildlife crime rangers across Africa and Asia to disrupt the trafficking. The gelatine lifting process visualised marks producing clear ridge detail on $52 \%$ of the Pangolin scales examined, with a further $30 \%$ showing the impression of a finger with limited ridge detail. The paper builds on an initial sociotechnical approach to establishing requirement, then it focuses on the methods and outcomes lifting fingermarks off Pangolin scales using gelatine lifters, providing an evaluation of the viability of using the lifters in practice.
\end{abstract}

\section{Keywords}

Wildlife Crime; Fingerprints; Pangolins; Gelatine Lifting; Crime Scene Investigation

\section{Introduction}

Recent media reports and a previous commentary by the authors, document the plight of the Pangolin and its current position as "the most trafficked mammal in the world" [1][2][3][4]. It is an elusive mammal, ranging from 30 to $100 \mathrm{~cm}$ in length and it is mainly nocturnal, feeding on ants and termites with a long protruding tongue [5]. They are described by some as scaly anteaters as all species are covered in hard keratinous tissue in the form of overlapping scales acting as a "flexible dermal armour" [6]. There are eight species, all protected under both national and international law and listed on the International Union for Conservation of Nature (IUCN) "Red List" of threatened species [7]. The Indian Pangolin (Manis crassicaudata), the Chinese Pangolin ( $M$. pentadactyla), the Sunda Pangolin ( $M$. javanica) and the Philippine Pangolin (M. culionensis) are the four species located throughout Asia. The remaining four species are in sub-Saharan Africa, and include the White-bellied Pangolin (Phataginus tricuspis), Giant Ground Pangolin (Smutsia gigantea), Temminck's Ground Pangolin (S. temminkii) and Black-bellied Pangolin (Uromanis tetradactyla) [4][8]. 
The extent of recorded and unrecorded trafficking of the Pangolin [9], has led to the Convention on International Trade in Endangered Species of Wild Fauna and Flora (CITES) categorising Pangolins as under threat of extinction due to the market for its scales and meat, along with considerable disruption to its habitat [5]. They are vulnerable to poaching, overexploitation and habitat destruction, and this is exacerbated by its slow reproduction rate [6]. Since 2000, it is estimated that one million pangolins have been taken and traded globally [7]. Between 2010 and 2015, 1270 seizure incidents were reported, involving 67 countries [10]. In 2019, one of the largest ever seizures involved 14 tons of scales being seized on a shipping container in Singapore [11]. The illegal pangolin trade has increased significantly [12], however, the seizures may only represent as little as $10 \%$ of the true volume of pangolins being illegally traded [13]. The demand is fuelled through traditional medicine, with some advertising Pangolin scales as an aid to relieve the symptoms of asthma, arthritis and to help lactation.

Defining the actions of the poacher is essential as it helps appraise the forensic evidence potential available on the scales. With this in mind, World Animal Protection [14] outline the brutality of the poachers during the 'processing' of the Pangolin for its meat and scales. They are hunted up trees and on ground, if they are in trees, the tree is cut down and they are caught or they are "smoked out". If seen on the ground the Pangolin, sensing it is in danger, rolls itself into a ball and the animal is then lifted and placed in a bag by the poacher. The meat and scales are the main commodity, with the scales being pulled off by hand and bagged for transportation and trafficked according to demand. The actions are heinous and cruel with the Pangolin subjected to unbearable suffering. The point of departure for this paper is the visualisation of fingermarks on the scales, which is a possibility if the scales are pulled from the body of the pangolin, however as Table 1 shows, there are other sources of evidence, potentially providing both associative and species information.

Currently, the forensic examination of seized Pangolins and Pangolin scales is limited, and there is a dearth of information in the literature. There is work outlining the use of DNA to identify protected species [15], and on scientific information relating to the Pangolin scales and trafficking [6][5][4], but little research on recovering forensic trace materials off Pangolin scales specifically.

The use of the forensic sciences in wildlife crime and its potential is well documented by established laboratories such as the Trace Network [16] and the US Fish and Wildlife Service [17]. Novel research on forensic trace analysis is currently isolated to a small, but growing body of relevant work, including Weston-Ford, Moseley, Hall, Marsh, Morgan and Barron [18], outlining powdering techniques to develop fingermarks on ivory. Other relevant research by McMorris, Farrugia and Gentles [19] developed methods to recover fingermarks on feathers, and wildlife DNA forensic investigation research is far more developed, albeit this is more to do with species identification and tracking (See: [20][21][[22]). Apart from this, there is little research on novel methods and techniques to visualise and capture trace evidence on wildlife contraband, and no reports in the literature on recovering fingermarks off Pangolin scales.

In more general terms, the use of fingerprints in investigations has a long history [23]. Latent, patent and physical imprint impressions are often left by the friction ridge detail present on fingers, palms and feet when pressed onto a surface. It is reasonable to assume the person pulling Pangolin scales from the body will leave fingermarks as marks are often left by secretions present on the ridges or, by touching dust or debris on a surface and then leaving an impression of the ridge patterns and associated detail. Additionally a contaminant present on the ridges, such as blood, can be transferred to the surface. In regards to the marks, they can be enhanced with lighting and photographed, if patent, or visualised with chemical processes and then photographed and / or lifted, if they are latent. A gelatine plate, with its low-tac adhesive surface, can be used to lift marks in dust on smooth surfaces, 
or in certain conditions, the gelatine plates can lift untreated latent marks on non-porous surfaces [24].

The treatment approach is determined by the type of surface and a range of contextual parameters which are evaluated by the practitioner. For example porous or non-porous surfaces will require different techniques, non-porous may be suitable for powdering, cyanoacrylate fuming, and / or vacuum metal deposition [25], or for porous surfaces methods of staining will be used to get to the amino acids in the fingermark residue absorbed into the porous material. These treatments include Ninhydrin or, 1, 8-Diazafluoren-9-one (DFO) and 1,2-indanedione-zinc [25]. The chemical processes, whether on non-porous or porous materials, will react with specific constituents in the residue mark producing a colour change visualising the deposited ridge detail, making it either optically visible, or made visible under certain wavelengths of light [26]. However, the presence of the mark is reliant on sufficient amounts of the residue being present, the surface structure being suitably receptive to hold the mark, and there being some form of impression of the ridge detail left behind with limited disruption to the mark after its deposition. The absence of a mark, despite an item being handled, is not uncommon as the process of fingermark deposition, search, visualisation and recovery is the victim of many variables affecting the overarching process, notwithstanding the fingerprint shedding capability of the donor themselves. There are several detailed guides to the appropriate sequential use of fingermark development processes, for example the Centre for Applied Science and Technology Fingermark Visualisation Manual [25].

The operational context of wildlife crime rangers in country, and their views, was the predominant motive for the chosen technique in this paper. It is not always possible to deploy an optimised fingermark development and recovery process in every circumstance. It is sometimes determined by the resources available and the operational possibilities in the given situation, which also includes the personal risk to rangers operating in areas where poaching is prevalent. Often within certain regions access to the necessary chemicals and resources are not possible and the practitioners, or wildlife crime rangers in this instance, need to adapt accordingly. Through multiagency collaboration, the authors' adapted the methods selected in this paper to fit the working requirements and findings from visits to the agents in three regions, this included Benin, India and Kenya. This required a 'sociotechnical' approach, which meant researchers going where the work was taking place, liaising with the wildlife crime professionals, watching, learning, understanding both the social and technical aspects of the work they do, and then adapting techniques relevant to practitioner requirements.

The multiagency interaction outlined above, fostered a collaborative ethos used to identify prevalent issues and research requirement. Frontline agencies in the country along with the UK Border Force and the Zoological Society London (ZSL) worked with researchers to establish the aim and objectives. The aim for this study was to evaluate the suitability of gelatine lifters to lift and visualise fingermarks on Pangolin scales. The supporting objectives were to:

- to perform an assessment of the ridge detail quality of gelatine lifted fingermarks off Pangolin scales; and

- To appraise the functionality of gelatine lifters for wildlife crime purposes

To the authors' knowledge, this is the first time methods have been used to visualise marks on Pangolin scales. The research design has been a collaboration of wildlife crime experts on the ground, to produce a requirement from the end-user, based on their needs, with methods selected according to the operational context. This approach provides deployable and usable techniques that has the highest probability of working, in that, it is straightforward and effective providing wildlife crime 
enforcement officers with tools and techniques adapted to their purpose and sympathetic to their operational environment.

Table 1: Provides an overview of the potential evidence available.

\begin{tabular}{|c|c|}
\hline Evidence Potential: Pangolin Scales & Evidence potential: Gelatine Lifters \\
\hline $\begin{array}{l}\text { Ridge detail: Recovered off the surface, } \\
\text { potential links to anyone handling the scales. }\end{array}$ & $\begin{array}{l}\text { Ridge Detail: The ability to lift fingermarks from } \\
\text { the scale surface, could be scanned or } \\
\text { photographed and images disseminated. }\end{array}$ \\
\hline $\begin{array}{l}\text { Surface DNA: Possibilities for DNA from } \\
\text { smudged fingermarks and ridge detail on the } \\
\text { surface. }\end{array}$ & $\begin{array}{l}\text { DNA: Lifts of smudged marks or ridge detail } \\
\text { used for DNA analysis }\end{array}$ \\
\hline $\begin{array}{l}\text { Pollen / Mycology: Traces of pollen and fungal } \\
\text { spores on the surface of the scale may provide } \\
\text { indication of origin, or provenance. This could } \\
\text { be useful for generating intelligence, linking } \\
\text { with other evidence gathered. }\end{array}$ & $\begin{array}{l}\text { Pollen / Mycology: Traces of pollen on the } \\
\text { surface potentially lifted off the scale, and } \\
\text { analysed to provide intelligence. }\end{array}$ \\
\hline $\begin{array}{l}\text { Soil / Traces: Similar to pollens and fungal } \\
\text { spores, profiling the soil types adhering to the } \\
\text { scale, including the layers and nature of the } \\
\text { trace, could determine specific regionality. }\end{array}$ & $\begin{array}{l}\text { Soil / Traces: Traces of soil lifted and present } \\
\text { on the lifters can be recovered and analysed. }\end{array}$ \\
\hline $\begin{array}{l}\text { Scale Morphology and DNA: Provides details of } \\
\text { species, location of the scale on the body, etc. }\end{array}$ & $\begin{array}{l}\text { Functionality of Gelatine Lifters: Lifts taken at } \\
\text { scene off wildlife contraband could provide a } \\
\text { receptacle for several evidence types. The lifters } \\
\text { can be covered, protected and packaged at the } \\
\text { scene and disseminated for analysis. }\end{array}$ \\
\hline
\end{tabular}

\section{Method:}

Materials:

The gelatine plates used in this study were BVDA black lifters [27]. They were scanned using the BVDA GLScan system. The GLScan scans were used to grade the marks in both the preliminary studies and for the time dependent study.

Approximately 200 Pangolin scales, weighing 14 grams, from varying African species were obtained on loan through UK Border Force and the UK Department for Environment, Food and Rural Affairs (DEFRA). The Pangolin scales varied in size and shape, the range of scales can be seen in figure 2 . The 
scales are part of a stored collection of seized items that the UK Border Force and DEFRA have collected over recent years and maintain for further inquiries and research. They were not linked to any ongoing case or incident. The scales were untouched between initial seizure and throughout storage, many containing visible signs of ingrained debris on the scale surface.

The scales selected for the study were based on their size and offered sufficient surface area to be gripped by participants. In the preliminary study, 25 scales were used measuring on average $3.81 \mathrm{~cm}$ in length and $1.27 \mathrm{~cm}$ in width. The exact species of the Pangolin was unknown, the determination of species from the scale alone is problematic, even for species experts, unless they are significantly morphologically different. Nevertheless, it is unnecessary to know the exact species as the aim was isolated to establishing the viability of the gelatine lifters to visualise fingermarks lifted off the scales. The scales were not cleaned and were taken directly from the container they were stored in. For the second study, 48 scales of similar general measurements to the preliminary study were used under the same conditions. The keratin surface of all scales used could be clearly seen, despite some showing signs of the ingrained dirt mentioned previously, interestingly, this was more apparent on the underside of the scale. For all studies, after gelatine scanning and photography, Adobe Photoshop was used to display the lift images through which the marks were graded. The RAW images from the GLScan system were imported to the Photoshop software and enhanced using brightness and contrast where necessary.

Figure 1: An example of the range of Pangolin scales used throughout the study
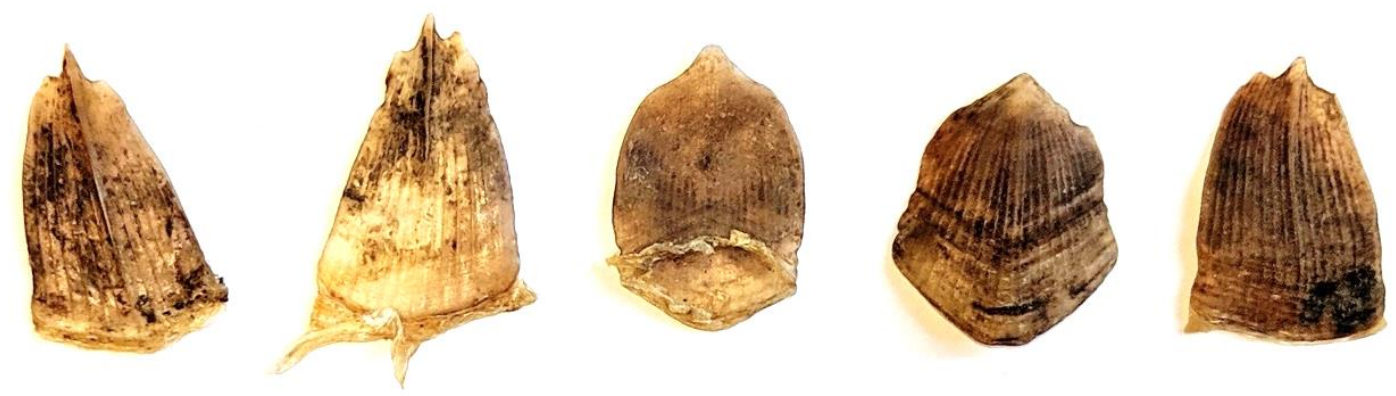

Preliminary Studies to Verify the Suitability of Gelatine Lifting for Visualising Fingerprints on Pangolin Scales:

For the preliminary evaluation, 25 Pangolin scales were used. The scales were carefully labelled away from the point of contact and placed on a flat surface. Participants $(n=5)$ were asked not to wash their hands within 30 minutes of deposition and they then gripped five scales, one at a time, between their thumb and forefinger, with the right hand. The participants lifted the scales and placed them back on to the flat surface and the scales were left for 48 hours at room temperature in a cupboard in a secure laboratory. The BVDA black gelatine lifters were removed from refrigerated storage and allowed to reach room temperature and then cut in to $5 \mathrm{~cm}$ by $5 \mathrm{~cm}$ squares. Just before applying them to the scales the protective acetate covering was removed, one gelatine lifter was placed on a flat surface sticky side up, the Pangolin scale was placed on top and a second gelatine was pressed on to the scale. The lifters were firmly pressed together, sandwiching the scale, then pulled apart and placed on the GLScan platform. Five scales were used per participant, with two gelatine lifts from each scale, one for each side, capturing the impression from thumb and forefinger. This produced 10 marks per participant, giving a total of 50 lifts. Each gelatine lift was then scanned and modified using Adobe Photoshop. The modifications included increasing or decreasing brightness and adjusting contrast to optimise the mark in terms of its clarity, the scanned marks were also inverted to provide a black 
fingermark of a light background. All marks were then graded using a standard Home Office grading scheme outlined in Sears et al. [28]. Table 2 outlines the grades and categories used.

Table 2: Grading scheme used for marks [28]

\begin{tabular}{|l|l|}
\hline Grade & Level of Detail \\
\hline 0 & No evidence of mark \\
\hline 1 & Some evidence of contact but no ridge detail \\
\hline 2 & Less than $1 / 3$ of print showing clear ridge detail \\
\hline 3 & Between $1 / 3$ and $2 / 3$ of mark showing clear ridge detail \\
\hline 4 & Over $2 / 3$ of mark showing clear ridge detail \\
\hline
\end{tabular}

Time studies reviewing the suitability of Gelatine Lifting for Visualising Fingerprints on Pangolin Scales:

A second study was undertaken to verify the impact of a time delay on lifting from the scales using a new group of participants $(n=8)$. We selected four participants who were good depositors of fingermarks and four who were known poor depositors of fingermarks. All participants deposited fingermarks on six Pangolin scales and, as with the preliminary study, participants were told not to wash their hands within 30 minutes prior to deposition. Participants were instructed to use their thumb and forefinger on the right hand to grip the scale and lay marks, see figure 2 . The researcher held the end of the scale not being used with a pair of plastic tweezers and the participant gripped the other end for 5 seconds. Each participant repeated the process for all six scales, which were then labelled as 1 through to 6 with the participant's number, gender and age on a sticky white label wrapped around the end of the scale that had not been touched (Figure 3). This produced a total of 96 lifts.

Figure 2: Participants were requested to grip the scale between the thumb and forefinger

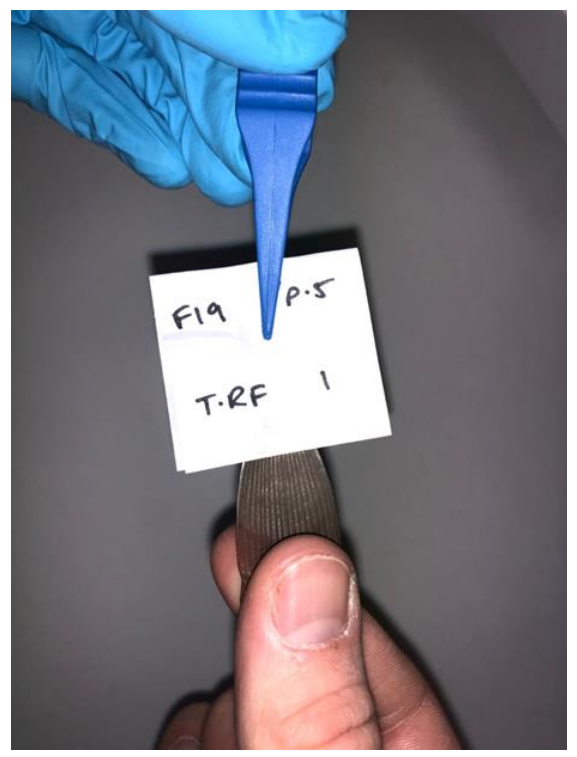

Figure 3: Each scale labelled recording the participant number and gender. 


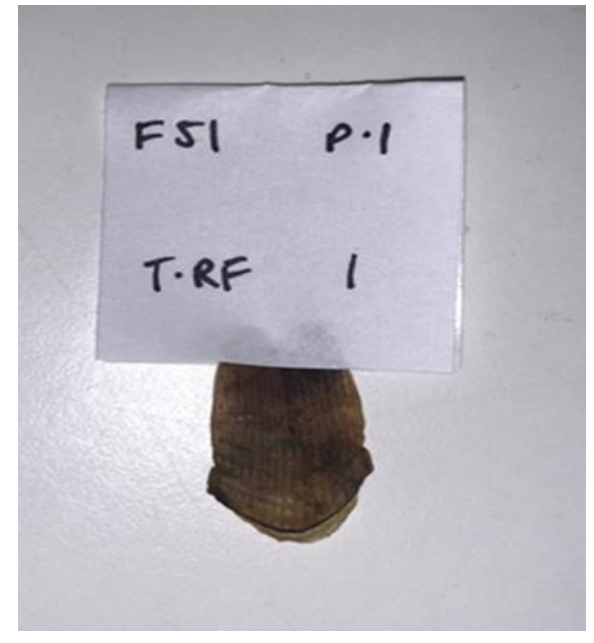

Participants deposited their fingermarks on each of the 6 scales at the same time, rubbing their hands together between each deposition. The first of these sets was used as a control sample, wherein the gelatine lifter was immediately used to lift from the scales. Time intervals were then set for the experimental group, the scales were processed at one week, two weeks, three weeks, two months and four month intervals after deposition.

The gelatine lifting sheets were cut into $5 \mathrm{~cm}$ by $5 \mathrm{~cm}$ squares for each scale. As with the preliminary study, two cut pieces of gelatine lifters were pressed onto either side of the scale at the same time and held together with a moderate pressure for 10 seconds. The scanning of small pieces of gelatine can be complicated by the gelatine curling at the edges, despite the vacuum on the scanner platform bed. Therefore, both sides of the lift were laid side by side and stuck down on to a transparent sticky backed acetate to ensure the gelatine lifters stayed flat. The two pieces of gelatine lifter were then placed into the BVDA GLScan platform and scanned. All fingermarks were assessed and categorised as a grade from 0 to 4 using the system recommended by CAST and seen in the Table 2 [28].

\section{Scanning Electronic Microscopy of Pangolin Scale Surface:}

The microstructure of the surface of the pangolin scales was studied using scanning electron microscopy. This was carried out to establish the porosity of the top and the bottom surface of the scale, enabling a better understanding of which fingermark visualisation processes are most likely to be effective. Several of the smaller scales were selected for examination, preparing some with the outer surface facing upwards, some with the inner surface facing upwards, and one scale from the tail region where the scale had a ' $V$ ' shape.

The scales were placed onto a conductive carbon adhesive disc on an aluminium stub. To prevent the non-conducting scales charging in the electron microscope, a gold coating was first sputtered onto the samples for approximately 2 minutes using an SEM Coating Unit E5100 (Polaron Equipment Limited) with vacuum setting 0.2 Torr and current $0.2 \mathrm{~mA}$.

After gold coating, the scales were placed into a Pemtron PS-230 scanning electron microscope (SEM) (Pemtron Corp. Seoul, South Korea) fitted with an Oxford Instruments X-act energy dispersive x-ray spectrometer (EDS) system (Oxford Instruments plc, Abingdon, UK). The structure of the scales was examined in the secondary electron imaging mode with an accelerating voltage of $20 \mathrm{kV}$ at magnifications from approximately $\times 100$ up to $\times 5000$. 


\section{Results \& Discussion}

Preliminary Studies to Verify the Suitability of Gelatine Lifting for Visualising Fingerprints on Pangolin Scales:

The Pangolin scales used were firm and smooth with pronounced grooves running along the top aspect of the scale from root to tip. On the underside, the scales were less smooth, with ingrained dirt and staining visible. This is unsurprising considering the activities of the Pangolin, including burrowing and nocturnal foraging for ants and termites, evidently, detritus gets caught between the scales and on several of the gelatine plates debris could be lifted which included loose keratinous material. The underside of all the scales has keratinous material forming almost a diamond shape with the root end of the scale, this is at the articulation point with the Pangolin's skin (this can be seen in figure 1). The gelatine lifters used were rubber backed and, with the thickness of the gelatine, was yielding enough to be impressed into the grooves allowing the spurs of elevated material on the underside to press into the gelatine. In three of the lifts, this caused contact voids between the gelatine and the surface, this needed to be considered for future trials. To mitigate this, the gelatine needs to be pressed more firmly into the scale. Furthermore, the gelatine sometimes moved during the application, particularly if there was a build-up of detritus on the scale itself. The use of the flat based surface helped to mitigate this. On scanning, as outlined previously, the small pieces of gelatine had a tendency to curl at the edges, the suction on the GLScan flatbed mitigated this to an extent, but it was still an issue with some of the lifters. This causes the light in the scanner to reflect off the gelatine and results in a white out of the image. Sticking the rubber backing side of the gelatine lifter to a sticky acetate helped keep the gelatine lifter flat during both scanning and photography.

Out of the marks examined ( $n=50), 74 \%(n=37)$ exhibited ridge detail, $24 \%(n=12)$ showed some evidence of contact but no ridge detail and only one mark had no detail or evidence of contact, this is presented in figure 4 . There was no significant difference between the top and underside of the scales in regard to ridge detail quality. The scans also showed the imperfections from the surface of the scale clearly, in some of the scans this did affect the continuity of the ridge detail and the quality of the marks lifted, figure 5 demonstrates the lifted debris on the mark. Figure 6 provides examples of marks graded two, three and four.

Figure 4: Example of marks with grade zero and 1.

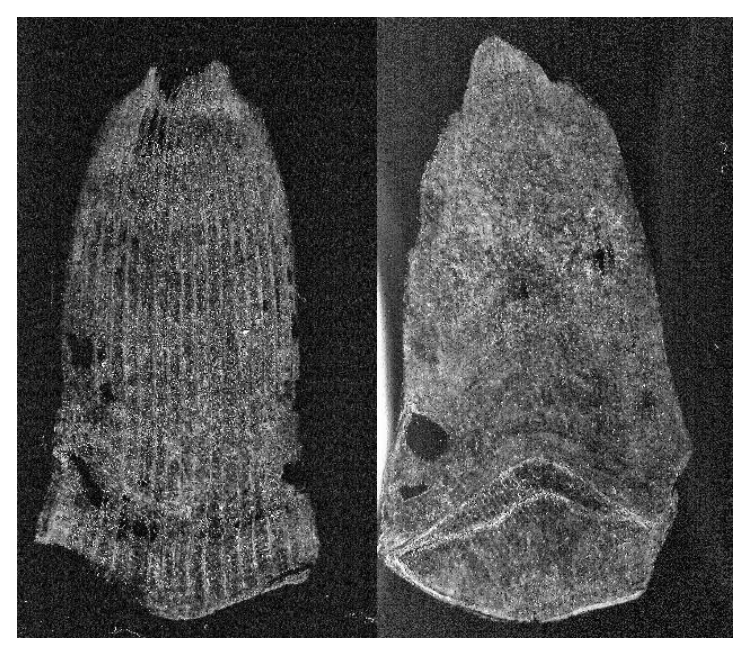

Figure 5: Examples of lifted debris from Pangolin scales 


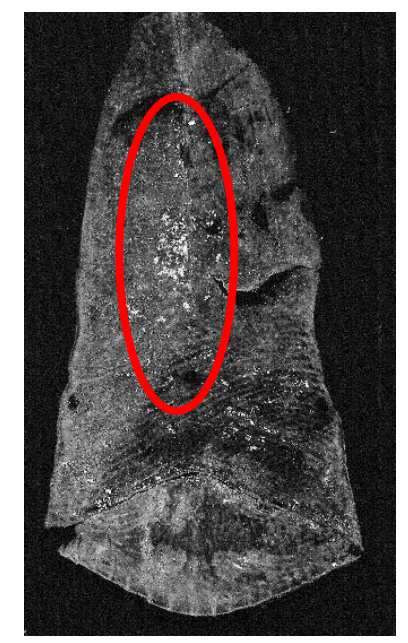

Figure 6: Example of marks graded 2, 3 and 4. Note the voids on mark (a) and (c).

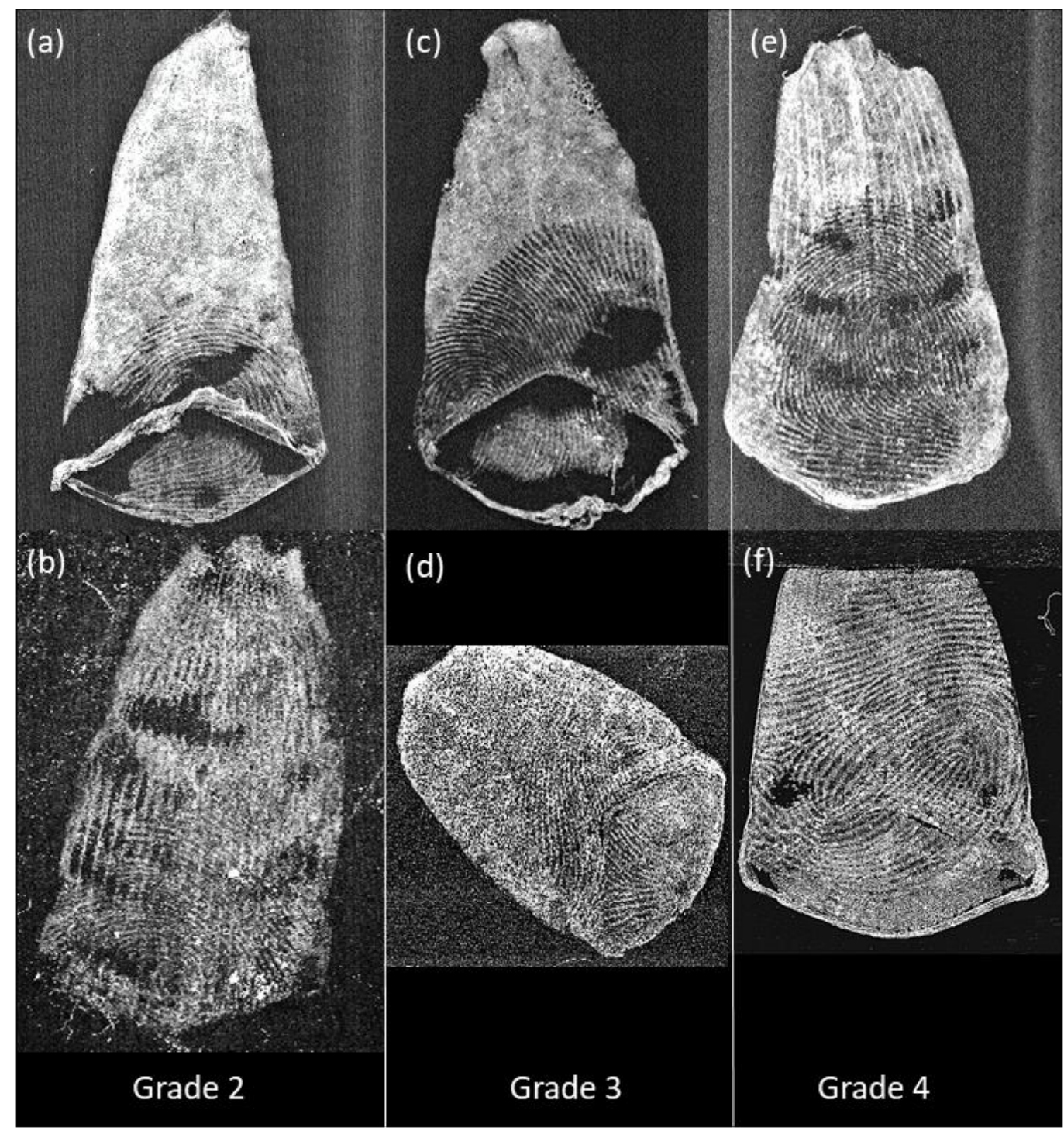

The suitability of Gelatine Lifting for Visualising Fingerprints on Pangolin Scales over time: 
Once it was ascertained through the preliminary studies that fingermarks could be lifted and visualised using gelatine lifters, the experiment was repeated for timed intervals over four months. As with all methods of fingermark visualisation, the quality of the ridge detail is determinable by the participant and by the surface integrity of the item, however in the preliminary studies the majority of lifts produced good quality marks, this was similar in the time study, but there was a higher proportion of lifts with no marks at all. As presented in figure 7 and figure 8, there was no noticeable attrition in detail over time, with the fingermark grade increasing slightly. As with the preliminary findings, the lifts off the back of the Pangolin scales were clearer overall, although the grades of lifts taken in month two showed clearer marks on the front of the Pangolin scale, this can be seen in figure 8. Table 3 shows the variance and standard deviation, it is interesting to see the marks for several of the participants is clustered, for example F58 is mostly grade 0 and 1, whereas M45 is clustered around grades of 3 and 4 . This is interesting as it shows the distinction between the good depositor of fingermarks and the poor depositor, with good consistency between the grades.

Out of the marks examined $(n=96)$, ridge detail was observed in $52 \%(n=50)$ with $30 \%(n=29)$ showing an impression of the fingermark with no ridge detail. In $18 \%(n=17)$ there were no marks present, this was an increase from the preliminary studies. The frequency of grades can be seen in figure 9.

Figure 7: Mean fingermark grades over the time intervals, with the grades for front and back combined.

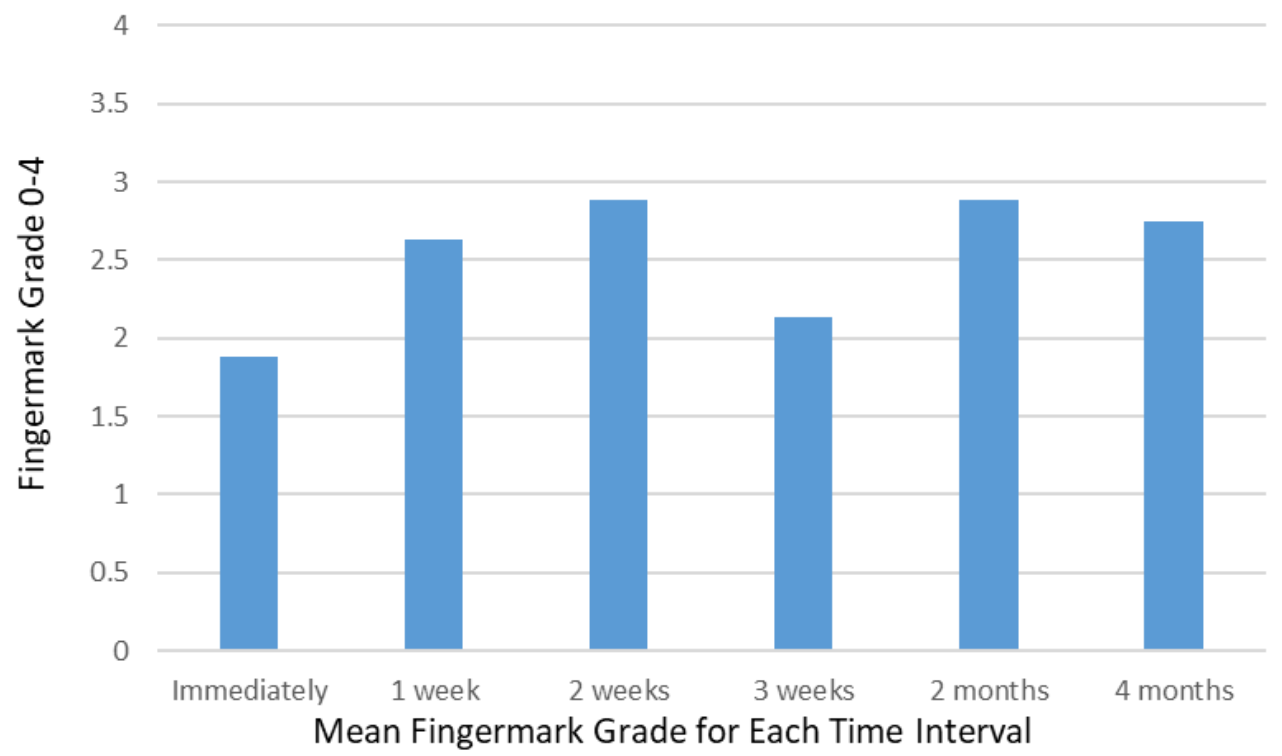

Figure 8: Mean fingermark grades of front and back lifted marks over time 


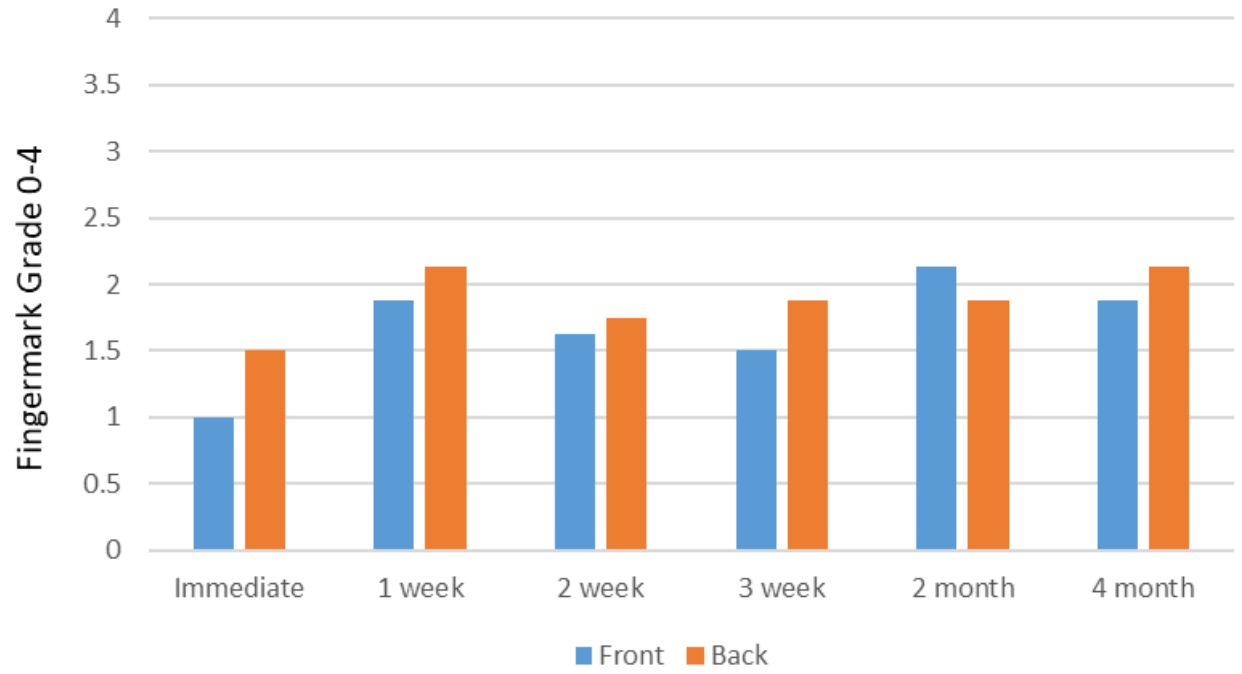

Mean Fingermark Grade for Each Time Interval, includes the difference between front and back.

Table 3: Mean scores for each participant from the second study, with standard deviation and variance

\begin{tabular}{|c|c|c|c|c|c|c|c|c|c|}
\hline Days & F19 & F20 & F26 & F51 & F56 & F58 & M45 & M20 & Mean \\
\hline 1 & 1 & 0 & 0 & 1 & 0 & 0 & 4 & 1 & 0.88 \\
\hline 1 & 2 & 2 & 0 & 2 & 1 & 0 & 4 & 1 & 1.50 \\
\hline 7 & 4 & 2 & 1 & 2 & 1 & 0 & 4 & 1 & 1.88 \\
\hline 7 & 4 & 3 & 1 & 2 & 1 & 1 & 4 & 1 & 2.13 \\
\hline 14 & 2 & 2 & 0 & 2 & 2 & 1 & 3 & 1 & 1.63 \\
\hline 14 & 1 & 3 & 1 & 2 & 1 & 0 & 4 & 2 & 1.75 \\
\hline 21 & 2 & 3 & 0 & 3 & 0 & 0 & 4 & 0 & 1.50 \\
\hline 21 & 1 & 4 & 1 & 3 & 1 & 1 & 4 & 0 & 1.88 \\
\hline 60 & 2 & 3 & 0 & 4 & 2 & 1 & 4 & 1 & 2.13 \\
\hline 60 & 2 & 3 & 0 & 3 & 1 & 1 & 3 & 2 & 1.88 \\
\hline 120 & 4 & 2 & 1 & 3 & 0 & 1 & 3 & 1 & 1.88 \\
\hline 120 & 4 & 2 & 2 & 3 & 1 & 1 & 2 & 2 & 2.13 \\
\hline Average & 2.42 & 2.42 & 0.58 & 2.50 & 0.92 & 0.58 & 3.58 & 1.08 & \\
\hline Std Dev & 1.19 & 0.95 & 0.64 & 0.76 & 0.64 & 0.49 & 0.64 & 0.64 & \\
\hline Variance & 1.41 & 0.91 & 0.41 & 0.58 & 0.41 & 0.24 & 0.41 & 0.41 & \\
\hline Variance & 1.41 & 0.91 & 0.41 & 0.58 & 0.41 & 0.24 & 0.41 & 0.41 & \\
\hline \multirow{3}{*}{$\begin{array}{l}\text { Average } \\
\text { Std Dev } \\
\text { Variance }\end{array}$} & 2.42 & 2.42 & 0.58 & 2.50 & 0.92 & 0.58 & 3.58 & 1.08 & \\
\hline & 1.19 & 0.95 & 0.64 & 0.76 & 0.64 & 0.49 & 0.64 & 0.64 & \\
\hline & 1.41 & 0.91 & 0.41 & 0.58 & 0.41 & 0.24 & 0.41 & 0.41 & \\
\hline
\end{tabular}


Figure 9: Distribution of fingermark grades from $0-4$ for the whole study

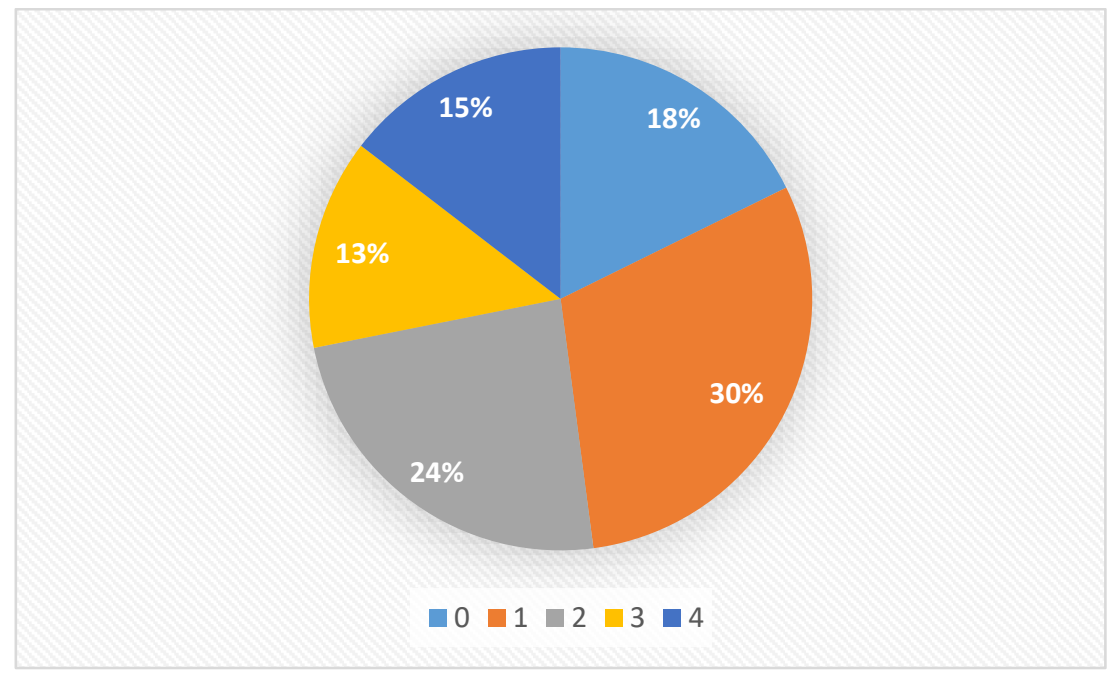

\section{Scanning Electron Microscope (SEM) images of the Pangolin Scale Surface:}

The upper surface of the scale (Figures 10a and 10c) showed a series of striations running along the length of the scale. At higher magnifications the surface appeared to be essentially non-porous, and the striations associated with localised surface damage. It is postulated that these striations arise from the pangolin scraping against hard materials such as stones as it performs activities such as digging. When the outer surface is viewed at a more oblique angle (Figures 10c), the striations remain visible and their topography can be more readily seen. Although the presence of the striations does give the surface some texture, this is not of the scale that would make the surface considered 'rough'.

The smooth, non-porous nature of the scale surface can be better seen in the micrographs of the underside (Figures 10b and 10d). Although the underlying surface is smooth, the underside of the scale appears to have collected more debris, possibly from the environment the pangolin is moving through. The trapping and collection of this debris is much more pronounced in the ' $V$ ' of the tail scale, (see Figures $10 \mathrm{c}$ and $10 \mathrm{~d}$ ). It is proposed that an analysis of this debris may yield useful information about the locality that the pangolin originated from.

The fact that the scale surface appears to be non-porous at a microstructural level would explain why the gelatine lifting process is effective. The fingermark residue will remain on the surface, and are still available to adhere to the lifter. The non-porous nature of the surface has been observed in previous SEM studies of the surface of pangolin scales, see: Wang et al, [6].

\section{Practical Considerations of using Gelatine Lifters for Pangolin Scales:}

The gelatine lifters are an effective method for lifting and visualising fingermarks off Pangolin scales. In all experiments, the outline of the mark or the ridge detail can be clearly seen in the majority of lifts. The studies were undertaken in a laboratory environment and further field studies are required to appraise and hone the operational utilisation of the lifters. Nevertheless, the significance of the outcomes, in terms of the quality of the fingermarks demonstrate that, if the fingermarks are present on the scales, gelatine lifters will work. They also provide both a useful and usable method that fits with the working context and environment of the wildlife crime rangers.

The initial engagement with wildlife crime rangers and practitioners demonstrated that the technique is straightforward and easily mastered. Capturing images on the gelatine lifters with cameras, or 
mobile phone cameras, allowed another level of functionality, enabling the digitised version of the image to be transferred for further analysis efficiently. The marks on the gelatine lifters can be captured using mobile phones, but further work is required to develop this approach. The gelatine lifters can potentially be used for other evidence types too, subsequently more thought is required regarding the sequential recovery of evidence off the lifters themselves. The ridge detail can be captured using the phone or camera, the lifters can then be packaged and preserved for more intrusive evidence extraction. The capture of the marks on the gelatine surface using mobile phones is an area the rangers regarded as essential to enable easy capture and dissemination. They all carry mobile phones and are very proficient with the use of the camera. However, holding the mobile phone at the appropriate angle, making sure it is perpendicular to the surface, and using some manner of light source to illuminate the marks on the gelatine surface is problematic. Therefore the research team are reviewing the use of a frame to act as a tripod, keeping the mobile hands free and square to the surface of the lift. The use of a portable and mobile screen that can be dropped down from the frame to create a darkened environment around the gelatine lifter is also being reviewed.

Another issue of using gelatine lifters in the field, particularly in warmer climates is that the gelatine starts to melt above $40^{\circ} \mathrm{C}$. This is particularly problematic if there is a need to lift off hot surfaces, for example cars in direct sunlight. In most circumstances the Pangolin scale surface itself will be significantly below $40^{\circ} \mathrm{C}$, but the environment and storage conditions of the gelatine lifters needs to be considered. The research team constructed bespoke packs for the rangers, which kept the lifters within a cool bag. Also in the pack are a series of accessories, including a roller, scissors and a flat template surface which can be used outdoors. In the initial trials of the kits by the rangers, there were no issues with the gelatine lifters in the heat, with the temperature ranging from $28-38^{\circ} \mathrm{C}$.

The sequence of capture needed to be considered to prepare the kits, including the necessary accessories for use in the field. In some circumstances, the acetate cover which is taken off the gelatine lifters before being applied to a surface can be replaced over the gelatine lifters after lifting the mark, re-alignment is achieved by cutting away a small bit of the corner before the lifter is used. Replacing the acetate cover is common for lifts with fingerprint powders, or where there is a large amount of dust lifted, but it is problematic where the marks are straight lifted or where DNA may be considered at a later stage. Therefore, small plastic wallets are being reviewed to transport the gelatine lifters from the scene.

In regards to the sequence of analysis after lifting, if other evidence types, such as DNA and trace evidence are required, the fingermarks on the gelatine lifters should be captured first with a mobile phone, camera or scanner. The gelatine lifters can then be packaged and preserved for any following treatments, for example DNA and trace evidence recovery. Further work is being undertaken to review the effectiveness of further treatments. The initial parameters which shaped this project was reviewing a 'one-lift' method that provided multiple evidential opportunities. The gelatines are being reviewed in regards to DNA and trace recovery, which will be reported elsewhere. Early signs indicate DNA is present in the marks on the gelatine lifters in low quantities. Future research will look to hone the techniques and look at alternative gelatine lifters of varying materials to lessen the impact on the DNA but maintain the fingermark quality. As outlined in Table 1, the aim is to review where and how the gelatine lifters can be used to gather evidential information to inform the varying aspects of the wildlife crime investigations in multiple contexts. For example, there may be ridge detail present that will potentially link to an individual having contact with the scale, similarly if there is a smudge or mark with no identifiable ridge detail, then, potentially, DNA could be useful. For scale seizures away from the Pangolin's habitat, if traces such as pollen and soil deposits can be analysed off the gelatine or 
directly from the scale itself, this may provide provenance, and provide intelligence in regards to origin and any patterns of trafficking behaviour.

\section{Conclusion}

This research has provided the first review of methods to lift and visualise fingermarks off Pangolin scales. The gelatine lifters are effective and show potential for being a usable and inexpensive method, meeting the needs of the end-user. This research is part of a preliminary phase of a broader project. Future studies will look at alternative types of gelatine lifters, methods to capture other evidence types off one gelatine lifter, and techniques to support the capture of fingermarks in the field using mobile phones. It is acknowledged that in regards to the disruption of wildlife crime contraband trafficking, this research is a small solution to a much bigger problem. However, the collaborative approach, engaging with the end-user and stakeholders with a vested interest and experience in the conservation of our wildlife and its habitats, designing novel approaches that can be reviewed and consolidated enables a shared development and exchange of ideas that have the best chance of working. It equips the wildlife crime rangers and has the potential to be a deterrent to would-be traffickers, and a usable tool to help save the Pangolin. 
Figure 10: Scanning Electronic Imaging Micrographs of two Pangolin scales, (a) and (b) upper side and underside of a flat scale and (c) and (d) upper side and underside of a tail scale.
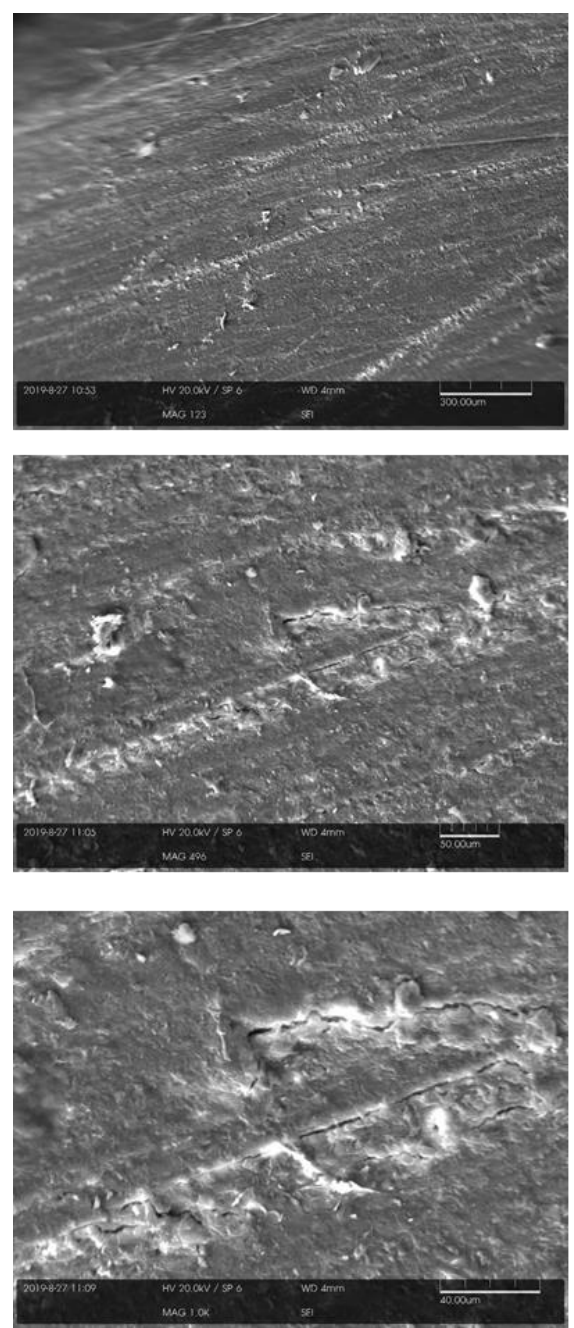

(a) Upper surface of $1^{\text {st }}$ scale
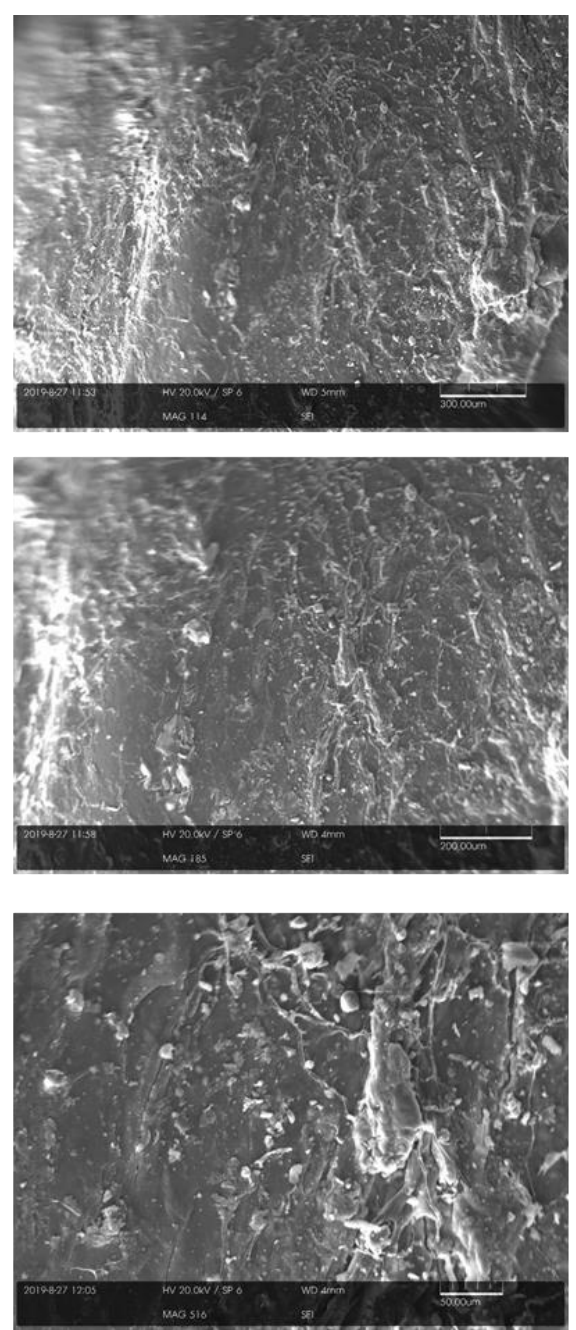

(b) Underside of $1^{\text {st }}$ Scale
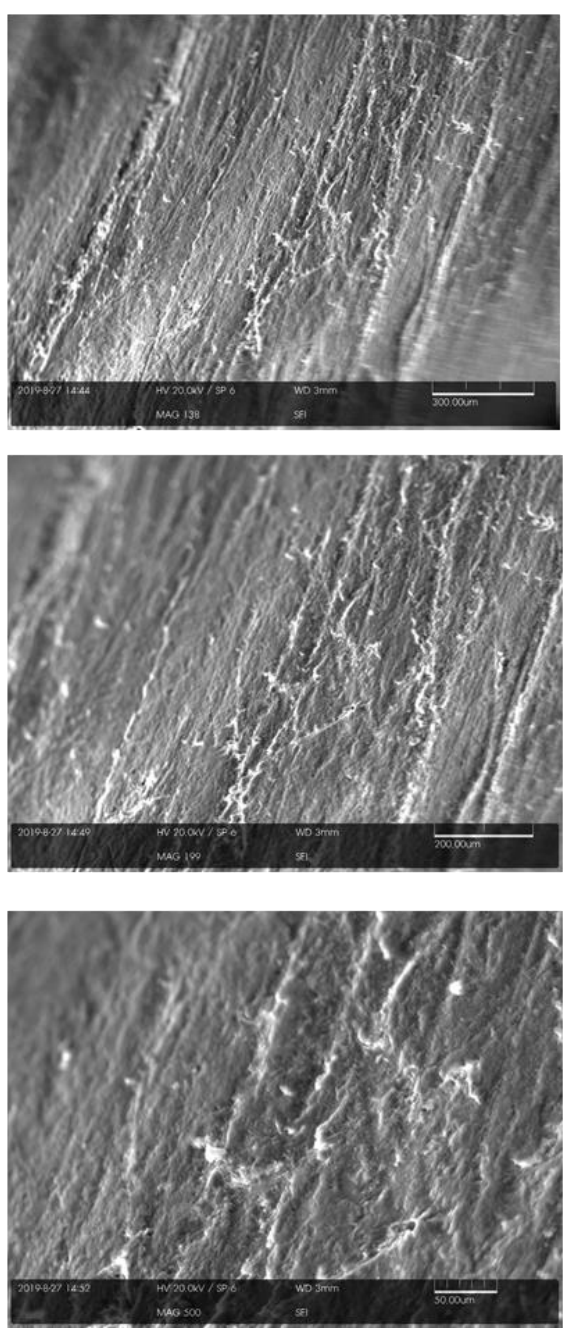

(c): Upper Surface of $2^{\text {nd }}$ Scale
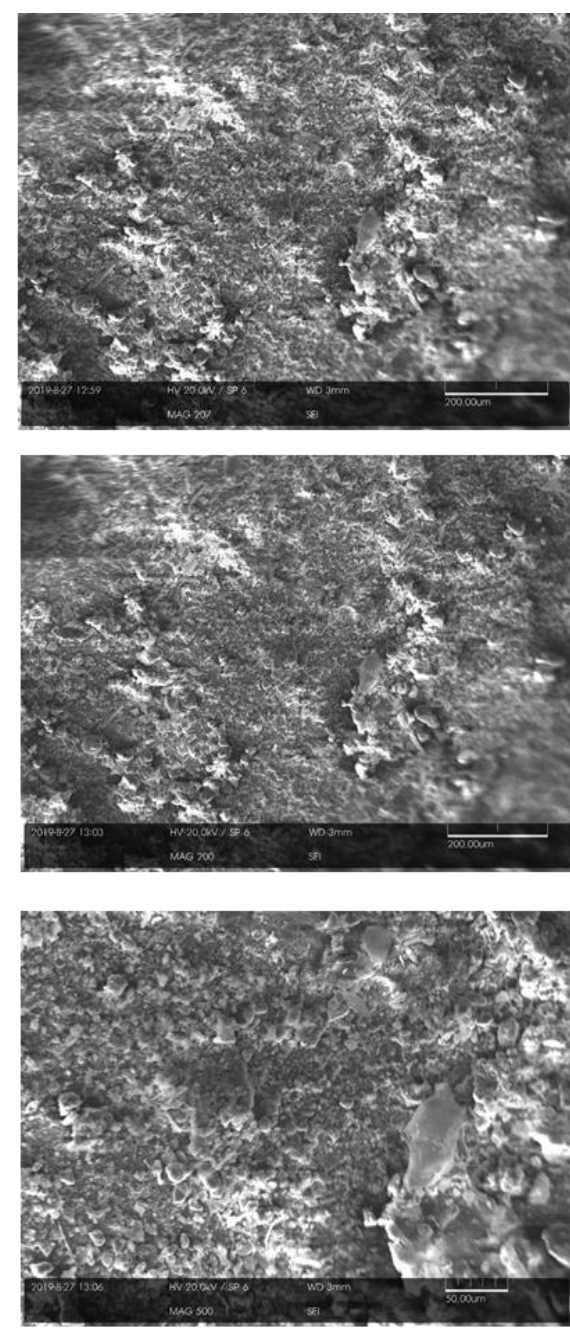

(d): Upper surface of $2^{\text {nd }}$ Scale 


\section{References:}

[1] Smith, P.A., Pamment, N., Cox, C., Reed, J., Chappell, B. and Plowman, C., 2019, Disrupting wildlife crime: The benefits of meaningful collaboration. Forensic Science International, 299; June, 2019. PP e1 and e2.

[2] Bale, R., 2018, How Simple Forensic Fingerprinting Could Help the World's Most Trafficked Mammal. National Geographic, July 6, 2018.

[3] BBC, 2018, Fingerprint tech could help catch pangolin poachers. BBC Online. June 282018.

[4] Challender, D. W. S., Waterman, C., \& Baillie, J. E. M. (2014) Scaling up pangolin conservation. Retrieved from IUCN SSC Pangolin Specialist Group: http://cmsdata.iucn.org/downloads/scaling up pangolin conservation 280714 v4.pdf

[5] Heinrich, S., Wittmann, T. A., Prowse, T. A. A., Ross, J. V., Delean, S., Shepherd, C. R., \& Cassey, P. (2016). Where did all the pangolins go? International CITES trade in pangolin species. Global Ecology and Conservation, 8, 241-253

[6] Wang, B., Yang, W., Sherman, V.R. and Meyers, M.A., 2016, Pangolin armor: Overlapping, structure, and mechanical properties of the keratinous scales. Acta Biomaterialia, 41 pp 60-74

[7] IUCN, 2018, IUCN. (2018). The IUCN Red List of Threatened Species. Version 2018-2.

[8] Soewu, D. A. \& Sodeinde, O. A. (2015). Utilization of pangolins in Africa: Fuelling factors, diversity of uses and sustainability. International Journal of Biodiversity and Conservation, 7(1), 1-10

[9] Zhang, M., Gouveia, A., Qin, T., Quan, R. \& Nijman, V. (2017). Illegal pangolin trade in northernmost Myanmar and its links to India and China. Global Ecology and Conservation, 10, 23-31

[10] UN Environment, 2018, Wildlife crime: Pangolin trade still flourishing despite ban. February 12, 2018.

[11] McKirdy, E., 2019, Record haul of pangolin scales highlights Chinese and Vietnamese demand for endangered species. CNN News. April 12, 2019.

[12] Environment Investigation Agency, 2019, Record seizure of ivory and pangolin scales puts pressure on Vietnam to act on rampant illegal wildlife trade. July 23, 2019.

[13] World Wildlife Fund., 2018, Species: Pangolin. Retrieved from: https://www.worldwildlife.org/species/pangolin

[14] World Wildlife Protection, 2018, Pangolin poaching: the brutal reality. December 3, 2018. Available at:

https://www.worldanimalprotection.org.uk/news/pangolin-poaching-brutal-reality 
[15] Hsieh, H.M., Lee, J.C.I., Wu, J. H., Chen, C.A., Chen, Y.J., Wang, G.B., Chin, S.C., Wang, L.C., Linacre, A., and Tsai, L.C., 2011, Establishing the pangolin mitochondrial $D$-loop sequences from the

confiscated scales. Forensic Science International: Genetics. 5, pp 303-307

[16] Ogden, R. and Linacre, A., 2015, Wildlife forensic science: A review of genetic geographic origin assignment. Forensic Science International: Genetics. 18, pp 152-159

[17] FWS (2019) US Fish and Wildlife Service, Forensics Lab. Available at: https://www.fws.gov/lab/

[18] Weston-Ford, K.A., Moseley, M.L., Hall, L.J., Marsh, N.P., Morgan, R.M. and Barron, L.P., 2016, The retrieval of fingerprint friction ridge detail from elephant ivory using reduced-scale magnetic and non-magnetic powdering materials. Science and Justice, 56, pp 1-8

[19] McMorris, H., Farrugia, K. and Gentles, D., 2015, An investigation into the detection of latent marks on the feathers and eggs of birds of prey. Science and Justice, 55(2) pp 90-96

[20] Ogden, R., Dawnay, N. and McEwing, R., 2009, Wildlife DNA forensics-bridging the gap between conservation genetics and law enforcement.

Endangered Species Research, 9 pp $179-195$.

[21] Johnson, R.N., Wilson-Wilde, L. and Linacre, A., 2014, Current and future directions of DNA in wildlife forensic science. Forensic Science International: Genetics. 10 pp 1-11

[22] Masters, A., Ogden, R., Whetton, J.H. and Dawnay, N., 2019, Defining end user requirements for a field-based molecular detection system for wildlife forensic investigations. Forensic Science International, 301 pp 231 - 239

[23] Berry, J. and Stoney, D.A., 2001, History and Development of Fingerprinting. In Lee, H. and Gaensslen, R.E. (Eds.) Advances in Fingerprint Technology. London: CRC Press.

[24] Bleay, S.M., Bandey, H.L., Black, M. and Sears, V G., 2011, The Gelatin Lifting Process: An Evaluation of its Effectiveness in the Recovery of Latent Fingerprints. Journal of Forensic Identification, 61(6) pp $581-606$

[25] Home Office, 2014, Fingermark Visualisation Manual. London; Crown Copyright.

[26] Champod, C., Lennard, C.J., Margot, P. and Stoilovic, M., 2017, Fingerprints and Other Ridge Skin Impressions. London: CRC.

[27] BVDA, 2015, Gellifters. Available at: BVDA, 2019, http://www.bvda.com/en/gellifters 
[28] Sears, V.G., Bleay, S.M., Bandey, H.L. and Bowman, V.J., 2012, A methodology for fingermark research. Science and Justice, 52(3) pp 145 - 160 